\title{
Analysis of Reverse Flow for Single Phase Fluid Inside U-Tubes of Steam Generator
}

\author{
S.M. Wang \\ Department of Nuclear Energy Science and Engineering \\ Naval University of Engineering \\ Wuhan, China
}

H.G. Xiao

Department of Nuclear Energy Science and Engineering

Naval University of Engineering

Wuhan, China

\author{
D. Zhang \\ Department of Nuclear Energy Science and Engineering \\ Naval University of Engineering \\ Wuhan, China \\ X. Chu \\ Department of Nuclear Energy Science and Engineering \\ Naval University of Engineering \\ Wuhan, China
}

\begin{abstract}
The heat transfer and turbulent flow inside U-tubes in steam generator (SG) are studied. A flow model based on one-dimensional Oberbeck-Boussinesq equation is proposed and improved to analyze the phenomenon of reverse flow. The relationship between the mass flow velocity and pressure drop is established, and the characteristic mass flow velocity (CMFV) and characteristic pressure drop (CPD) are defined. The effect of inner diameter on the reverse flow in SG U-tubes can be obtained by analyzing the CMFV and CPD. The results show that the relationship between SG U-tube inner diameter and pressure drop is nonlinear and has a maximum, and the reverse flow happens more easily in SG U-tubes with the smaller inner diameter.
\end{abstract}

Keywords-U-tubes; reverse flow; instability; steam generator; single phase fluid

\section{INTRODUCTION}

The natural circulation will form when the flow is driven by the fluid temperature difference or density difference between heat sink and heat source in a closed-loop. The natural circulation ability has a significant influence on the inherent safety and operating performance of nuclear power plant (NPP), especially for the ship NPP. As one of the most important heat exchangers, the vertically inverted U-tube steam generator (UTSG) plays an important role in the safe operation of the NPP. According to the existing literature, the flow in the tubes of UTSG can be unstable and reverse flow will occur inside some U-tubes under a low flow rate condition. Because the reverse flow will reduce the pressure drop between the inlet and exit plenum, which leads to the decrease of mass flow velocity (MFV) and the increase of flow resistance, it has a negative effect on the operating safety of nuclear power plant (NPP). It is very necessary to analyze the reverse flow characteristic in the SG operated under natural circulation.

Based on the large-scale full height simulator of Westinghouse-type pressurized water reactor, Kukita et al. carried out the experimental study on the flow instability in U-tubes, and found that the mass flow distribution among the SG U-tubes was observably non-uniform[1]. Based on one-dimensional Oberbeck-Boussinesq equation, Sanders proposed a mathematical model of single-phase flow to investigate the reverse flow phenomenon[2]. Jeong et al. also set up a reverse flow model and analyzed the two and single phase flow characteristic inside a vertically inverted U-tube SG[3]. Sanders and Jeong et al. respectively obtained a relationship curve between the mass flow velocity (MFV) and pressure drop (PD) by using this flow model. They found that the relationship curve had a negative slope zone, and the reverse flow would occur in a low flow rate case while the system operated at the negative slope zone.

Yang et al. proposed the mathematical model to investigate the reverse flow inside UTSG U-tubes. They assumed that the reverse flow occurred inside the longer U-tube[4]. Zhang et al. also analyzed the flow rate distribution inside a UTSG in the low flow rate case by the CFD method. They pointed out that the reverse flow occurred inside the shorter U-tube[5]. Using the code Relap/Mod3.3, Hao et al. analyzed the natural circulation of single-phase flow for PWR by classifying U-tubes according to their length[6]. They shown that the relationship between the characteristic pressure drop (CPD) and the length of U-Tube was nonlinear when the reverse flow happened, and there existed a length of U-Tube which had the largest $\mathrm{CPD}[7,8]$. In the present work, a flow model is deduced from the conservation equations by using Oberbeck-Boussinesq approximation to investigate the effect of tube inner diameter on reverse flow.

\section{THE TheORETICAL MODEL}

Consider the fluid flow in the UTSG, as shown in Fig.1, one-dimensional Oberbeck-Boussinesq equation is employed, namely the fluid density difference is constant except in the gravity pressure drop. However, if the fluid temperature difference in the UTSG is large enough, the density difference should not be considered as a constant in the analysis. 


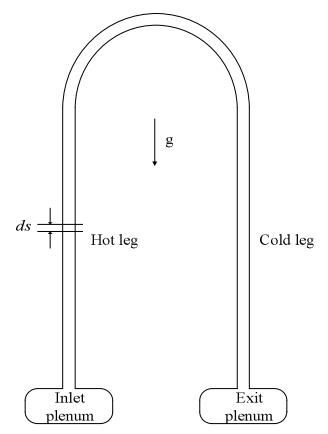

FIGURE I. U-TUBE SCHEMATIC

The dominant equations in the UTSG are given as follows[9]:

$$
\begin{gathered}
\frac{\partial \rho}{\partial t}+\frac{\partial \rho v}{\partial l}=0 \\
\frac{\partial \rho v}{\partial t}+\frac{\partial \rho v v}{\partial l}=-\frac{\partial p}{\partial l}-\frac{f}{D_{i}} \frac{\rho v^{2}}{2} \mp \rho g \\
\frac{\partial \rho c_{p} T}{\partial t}+\frac{\partial \rho v c_{p} T}{\partial l}=\frac{-P h\left(T-T_{\mathrm{sec}}\right)}{A}
\end{gathered}
$$

where, $\rho$ is the density; $t$ is the time; $v$ is the velocity; 1 is the coordinate along the U-tube length; $p$ is the pressure; $f$ is the flow frictional coefficient; $\mathrm{Di}$ is the tube inner diameter; $\mathrm{g}$ is the gravitational acceleration; signs "+" and "-" in Eq.(2) represent the falling (cold) leg and the rising (hot) leg in the U-tubes, respectively; $\mathrm{cp}$ is the specific heat; $\mathrm{T}$ is the temperature; $\mathrm{P}$ is the wetted perimeter; Tsec is the secondary side temperature of UTSG. A is the flow area; $h$ is the total heat transfer coefficient between the primary and secondary side fluid, which can be expressed as follows:

$$
h=\frac{1}{\frac{1}{\alpha_{i}} \frac{D_{o}}{D_{i}}+\frac{D_{o}}{2 k_{w}} \ln \frac{D_{o}}{D_{i}}+\frac{1}{\alpha_{o}}}
$$

where, $\alpha i$ and $\alpha_{0}$ are the inside and outside surface heat transfer coefficient of the tube respectively; kw is the heat conductivity of the tube of tube, and Do is the outside diameter of the tube.

According to Eq.(1), in the steady-state case, the mass flow velocity $(\mathrm{G}=\rho \mathrm{v})$ in inverted U-tubes is constant at any time. Because the fluid density changes along the U-tube, the flow velocity along the U-tube cannot be considered as a constant, and the flow model established by Sanders(1988) is limited. So it is necessary to improve the mathematical model. According to Boussinesq approximation, the density $\rho=\rho(T)$ can be expressed as follows:

$$
\rho(T)=\rho_{0}\left[1-\beta\left(T-T_{\text {sec }}\right)\right]
$$

where, $\rho 0$ is the fluid density under the temperature Tsec and operating pressure, $\beta$ is the thermal expansion coefficient.
For the steady-state condition, $\partial \mathrm{T} / \partial \mathrm{t}=0$. Then the temperature distribution along the U-tube length can be derived from Eq. (3) as follows:

$$
T(s)=T_{\mathrm{sec}}+\left(T_{i n}-T_{\mathrm{sec}}\right) \exp \left(-\frac{h \pi\left(D_{\mathrm{i}}+\delta\right)}{G c_{p} A} l\right)
$$

where, Tin is the inlet temperature; $\delta$ is the U-tube thickness; $\mathrm{G}$ is the mass flow velocity; Combining Eqs. (2), (5) and (6) and integrating it, the PD between the outlet and inlet plenum is obtained as follows:

$$
\Delta p=p_{\text {in }}-p_{\text {out }}=\frac{f L}{D_{i}} \frac{G^{2}}{2 \rho_{0}}-\frac{\rho_{0} g \alpha G A c_{p}}{\pi h\left(D_{\mathrm{i}}+\delta\right)}\left(T_{\text {in }}-T_{\text {sec }}\left(1-\exp \left(-\frac{L \pi h\left(D_{\mathrm{i}}+\delta\right)}{2 G A c_{p}}\right)\right)^{2}\right.
$$

where, $\mathrm{L}$ is the tube length. The first and second terms in the right side of Eq.(7) are the frictional and gravitational PD, respectively.

\section{ANALYSIS OF REVERSE FLOW}

A type of marine UTSG is chosen, which has the same outer and inner diameter and length of U-tube straight segment as well as component material. In order to discuss the effect of tube inner diameter on the flow instability, the inner diameter is set to $(10 \sim 25 \mathrm{~mm})$. Fig. 2 shows that the temperature along the U-tube length decreases exponentially, and temperature drop mainly occurs in the hot leg. So the average fluid density in cold leg is greater than that in hot leg. In addition, because of the insufficient heat exchanging between the primary and secondary side fluid, the average density in the hot and cold leg will decrease while the mass flow velocity increases, as indicated in Fig.3, which results in the decrease of gravitational pressure drop.

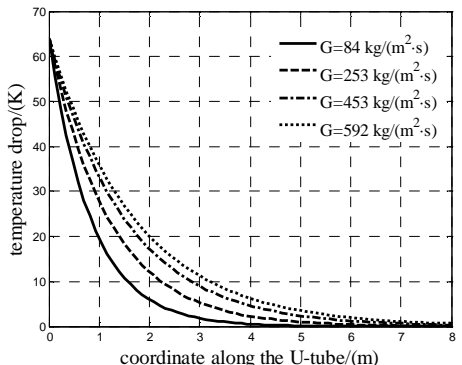

FIGURE II. TEMPERATURE DISTRIBUTION ALONG U-TUBE

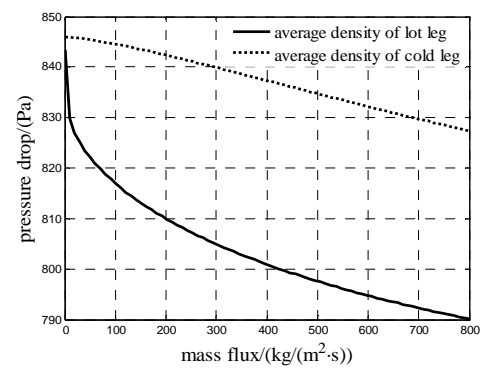

FIGURE III. AVERAGE DENSITY IN U-TUBE 


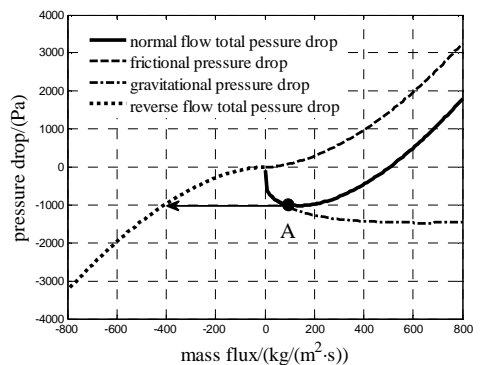

FIGURE IV. VARIATION OF PRESSURE DROP VERSUS MASS FLOW VELOCITY IN A U-TUBE

Fig.4 gives the variation of pressure drop versus mass flow velocity, which shows that the frictional pressure drop increases non-linearly, and the total pressure drop $\Delta p$ is the non-monotonic function of mass flow velocity. From Fig.4 it is also be found that even under the condition of negative total pressure drop a stable normal flow will be retained until the point $\mathrm{A}$ is approached. However, after the point $\mathrm{A}$ the further decrease of total pressure drop will leads to a flow instability that the normal flow transfers to the reverse flow suddenly ${ }^{[3]}$. The point $\mathrm{A}$ is called the characteristic point and notes the operating condition that the reverse flow will happen in the UTSG, which corresponds to the characteristic mass flow velocity (CMFV) and characteristic pressure drop (CPD).

The effect of inner diameter on the reverse flow inside U-tubes may be obtained by analyzing the CMFV and CPD for the given physic performance and other configuration parameters, as shown in Figs.5 and 6. Fig.5 shows that the CPD decreases non-linearly with the increase of U-tube inner diameter. And Fig.6 shows that the CMFV increases to a largest value, and then decreases with the increase of U-tube inner diameter.

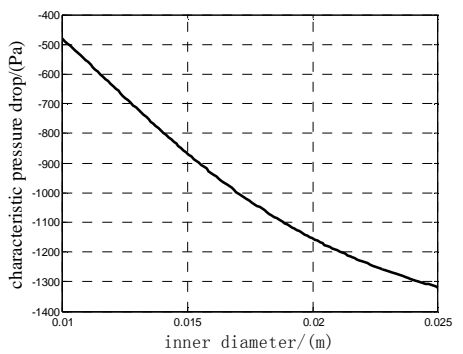

FIGURE V. VARIATION OF CHARACTERISTIC PRESSURE DROP VERSUS INNER DIAMETER

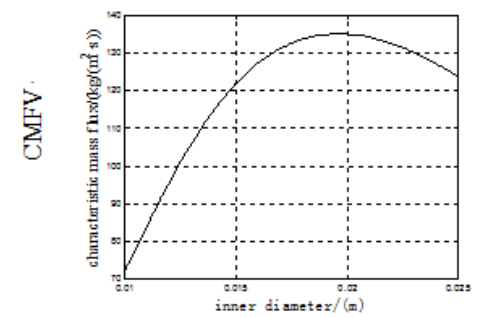

FIGURE VI. VARIATION OF CHARACTERISTIC MASS FLOW VELOCITY (CMFV) VERSUS INNER. DIAMETER
Furthermore, four U-tubes with different inner diameters are selected to analyze the effect of inner diameter on the curve of PD with MFV, as shown in the Figs.7 and 8. Figs.7 and 8 indicate that for the same mass flow velocity the pressure drop with smaller inner diameter is always larger than that with larger inner diameter, which is in accord with that obtained from Fig.5.

While the PD between the exit and inlet plenum persistently decreases, it will firstly reach the CPD in the U-tube with smaller inner diameter, so the reverse flow will firstly happen inside the U-tube of steam generator with smaller inner diameter.

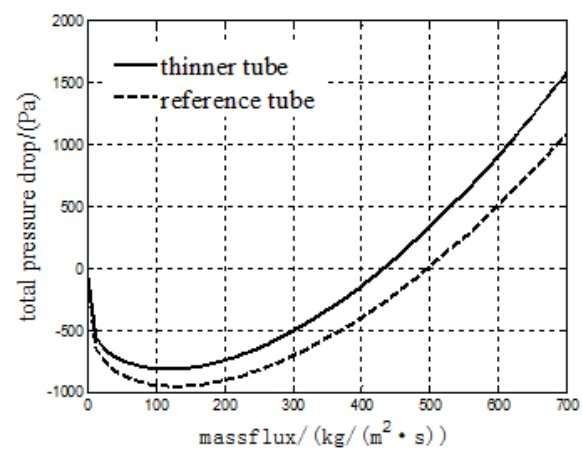

FIGURE VII. VARIATION OF PRESSURE DROP WITH MASS FLOW VELOCITY FOR TUBE INNER DIAMETER 14MM AND 16MM

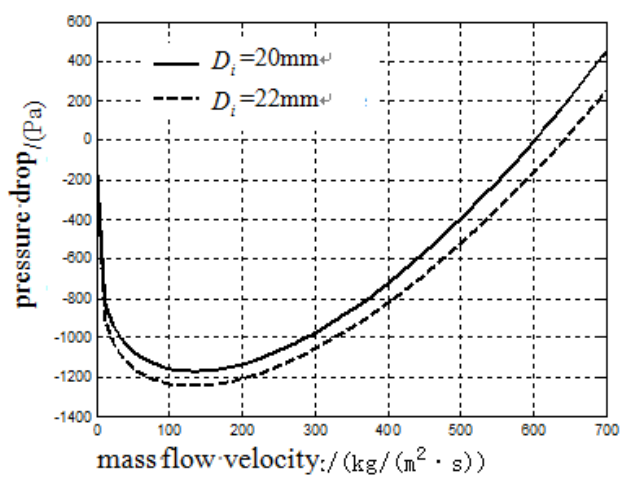

FIGURE VIII. VARIATION OF PRESSURE DROP WITH MASS FLOW VELOCITY FOR TUBE INNER DIAMETER 20MM AND 22MM

\section{CONCLUSIONS}

The heat transfer and hydraulic model of turbulent flow in U-tubes are investigated and improved. The effects of inner diameter of U-tube on the reverse flow are analyzed. There exists a point A, after which the further decrease of pressure drop will lead to a flow instability that the flow transfers from a normal to a reverse direction suddenly. The results show that the U-tube inner diameter influences the reverse flow. The characteristic pressure drop decreases non-linearly versus the increase of inner diameter of U-tube. And the variation curve of characteristic mass flow velocity with U-tube inner diameter has a maximum. For the same mass flow velocity the pressure drop with smaller inner diameter is always larger than that with larger inner diameter. Under the same other 
conditions the reverse flow will happen more easily inside the U-tubes of steam generator with smaller inner diameter.

\section{ACKNOWLEDGMENTS}

This research is supported by the National Natural Science Foundation of China (Project No. 11402300) and the Natural Science Foundation of Naval University of Engineering.

\section{REFERENCES}

[1] Kukita, Y., Nakamura, H., Tasaka, K., 1988, Non-uniform steam generator U-tube flow distribution during natural circulation tests in ROSA-IV large scale test facility. Nucl. Sci. Eng. 99: 289-298.

[2] Sanders, J., 1988, Stability of single-phase natural circulation with inverted U-tube steam generators. J. Heat Transfer 110: 735-742.

[3] Jeong, J.J., Hwang, M., Lee, Y.J., 2004, Non-uniform flow distribution in the steam generator U-tubes of a pressurized water reactor plant during single and two-phase natural circulations. Nucl. Eng. Des. 231: 303-314.

[4] Yang, R.C., Liu, J.G., Huang, Y.P., 2008, Investigation on reverse flow in U-tube of steam generator with natural circulation. J. Eng. Thermophysics 29: 807-810(in Chinese).

[5] Zhang, Y., Song, X.M., Huang, W., 2009, Research on flow distribution in UTSG under low flow rate condition. Nucl. Power Eng. 30: 56-59(in Chinese).

[6] Hao, J.L., Chen, W.Z., Chen, Z.Y., 2012, The development of natural circulation operation support program for ship nuclear power machinery. Ann. Nucl. Energy 50:199-205.

[7] Hao, J.L., Chen, W.Z., Zhang, D., 2013, Effect of U-tube length on reverse flow in UTSG primary side under natural circulation. Ann. Nucl. Energy 56: 66-70

[8] Hao, J.L., Chen, W.Z., Zhang, D., 2014, Flow instability analysis of U-tubes in SG based on CFD method. Prog. Nucl. Energy 70:134-139.

[9] Chen, W.Z., Yu, L., Hao, J.L., 2013, Thermal Hydraulics of Nuclear Power Plants. Chinese Atomic Energy Press, Beijing(in Chinese). 